\title{
Flood Mitigation on Mithi River using Detention pond, Mumbai, India
}

\author{
Khan Mujiburrehman ${ }^{1}$, Vinay Nikam², Gupta Kapil ${ }^{3}$ \\ ${ }^{1}$ Post Graduate Student, Department of Civil Engineering, Indian Institute of Technology, Mumbai, India \\ ${ }^{2}$ Research Scholar, Department of Civil Engineering, Indian Institute of Technology, Mumbai, India \\ ${ }^{3}$ Professor, Department of Civil Engineering, Indian Institute of Technology, Mumbai, India
}

\begin{abstract}
Mumbai city having an area of $437 \mathrm{sq} \mathrm{km}$ with a population of 12 million came to a complete halt due to the unprecedented rainfall of $944 \mathrm{~mm}$ during the 24 hours starting on $26^{\text {th }}$ July 2005; with $380 \mathrm{~mm}$ falling in just 3 hours between 14:30 to 17:30 and hourly rainfall exceeding $190 \mathrm{~mm} / \mathrm{hr}$. The severity of flood was such that it took 447 lives in Mumbai alone. The financial cost of flood was unprecedented and affected the entire commercial, trading, and industrial activity for 3 days.

The present study uses the HEC-HMS 3.4 (Hydrologic Engineering Centre's-Hydrologic Modeling System) and HEC-RAS 4.0 (Hydrologic Engineering Centre's-River Analysis System). The flow and water surface depth have been simulated for various flood scenarios using the model HEC-HMS 3.4 and HEC-RAS 4.0 respectively for rainfall intensities varying from $25 \mathrm{~mm} / \mathrm{hr}$. to $200 \mathrm{~mm} / \mathrm{hr}$ in increment of $25 \mathrm{~mm} / \mathrm{hr}$. Runoff and water surface depth at a upstream and downstream of detention pond have been obtained for various rainfall scenarious.. The simulation result shows maximum peak reduction of $21 \%$ by JVLR (JogeshwariVikhroli link road) flood detention pond. It has been seen that efficiency of JVLR detention pond decreases as the rainfall intensity increases above $50 \mathrm{~mm} / \mathrm{hr}$. Accordingly this study can be used in flood forecasting for various rainfall scenarios, sustainable development and flood management plans of Mithi River catchment.
\end{abstract}

Keywords: Urbanization, Flood, Mithi River, Flood detention pond, HEC-HMS 3.4, HEC-RAS 4.0.

\section{Introduction}

Many of the highly populated cities in the developing world that are located on the coast, for example, Mumbai, Bangkok, Dhaka and Jakarta, are highly susceptible to urban flooding. One of the main reasons cited for this is rapid urbanization, which causes changes in landscape owing to construction of urban infrastructures and changes in urban conveyances networks [1]. Mumbai city having an area of 437sq km with a population of 12 million came to a complete halt due to the unprecedented rainfall of $944 \mathrm{~mm}$ during the 24 hours starting on $26^{\text {th }}$ July 2005 ; with $380 \mathrm{~mm}$ falling in just 3 hours between $14: 30$ to $17: 30$ and hourly rainfall exceeding $190 \mathrm{~mm} / \mathrm{hr}$ [2]. Determining the extent of flooding is an important role of the water resources community and provides a vital service to planners and engineers [3]. Precipitation-runoff models have been widely used through the last century to formulate a reliable relationship between the precipitation (input of the model) and runoff (output of the model), [4]. Simulation of urban hydrology is an important part of evaluating management scenarios, including analysis and design of best management practices (BMPs) and sewer systems, and effects of land use changes [5]. The simplest rational equation models with a "runoff coefficient" have been introduced to determine the total runoff of an event by multiplying the runoff coefficient with the total rainfall [6] and [7]. The Hydrologic Engineering Center's Hydrologic Model System (HEC-HMS) is a computer program that can be used to model precipitation-runoff processes of dendritic watershed systems. It is designed to be applicable to a wide range of geographic areas for solving a broad range of problems. Runoff hydrographs from a HEC-HMS model can be used directly or by other software for studies of water availability, urban drainage, flood forecasting, future urbanization impact, reservoir spillway design, flood damage reduction, floodplain regulation, wetlands hydrology, and systems operation. Hicks et al. [8] studied the suitability of HEC-RAS for flood forecasting through an application to the Peace River in Alberta (Canada) and was shown that accuracy was comparable to more sophisticated one dimensional hydraulic model. The analysis of urban flooding problem and evaluation of flood control structure have been carried out by using the HEC-HMS 3.4 and HECRAS 4.0 model. The current paper evaluates the efficiency of JVLR detention pond on Mithi River for various rainfall scenarios.

\section{Catchment Description}

Greater Mumbai comprises Mumbai, South Salsette and Trombay Islands, bounded by $18^{\circ} 53^{\prime}$ and $19^{\circ}$ $20^{\prime}$ north latitude and $72^{\circ} 45^{\prime}$ and $73^{\circ} 00^{\prime}$ east longitude. Mumbai has ridges along its western and eastern sides. Mumbai city receives seasonal rainfall for four months, from June to September. Average rainfall is $2500 \mathrm{~mm}$, out of which 70 per cent is during July and August only. Mumbai is lined on the west by Arabian sea and is 
intercepted by number of creeks (Mahim, Mahul and Thane creeks), rivers (Mithi, Dahisar, Poisar and Oshiwara rivers, and their tributaries) and a complex nallah (drain) system [9]. The catchment considered in this study is Mithi River catchment which is located between north latitudes of $19^{\circ} 1 ' 36^{\prime \prime}$ and $19^{\circ} 10^{\prime} 9^{\prime \prime}$ and east longitudes of 72 49'59" and 72 56'33". The location of the Mithi River has been shown in Fig 1.

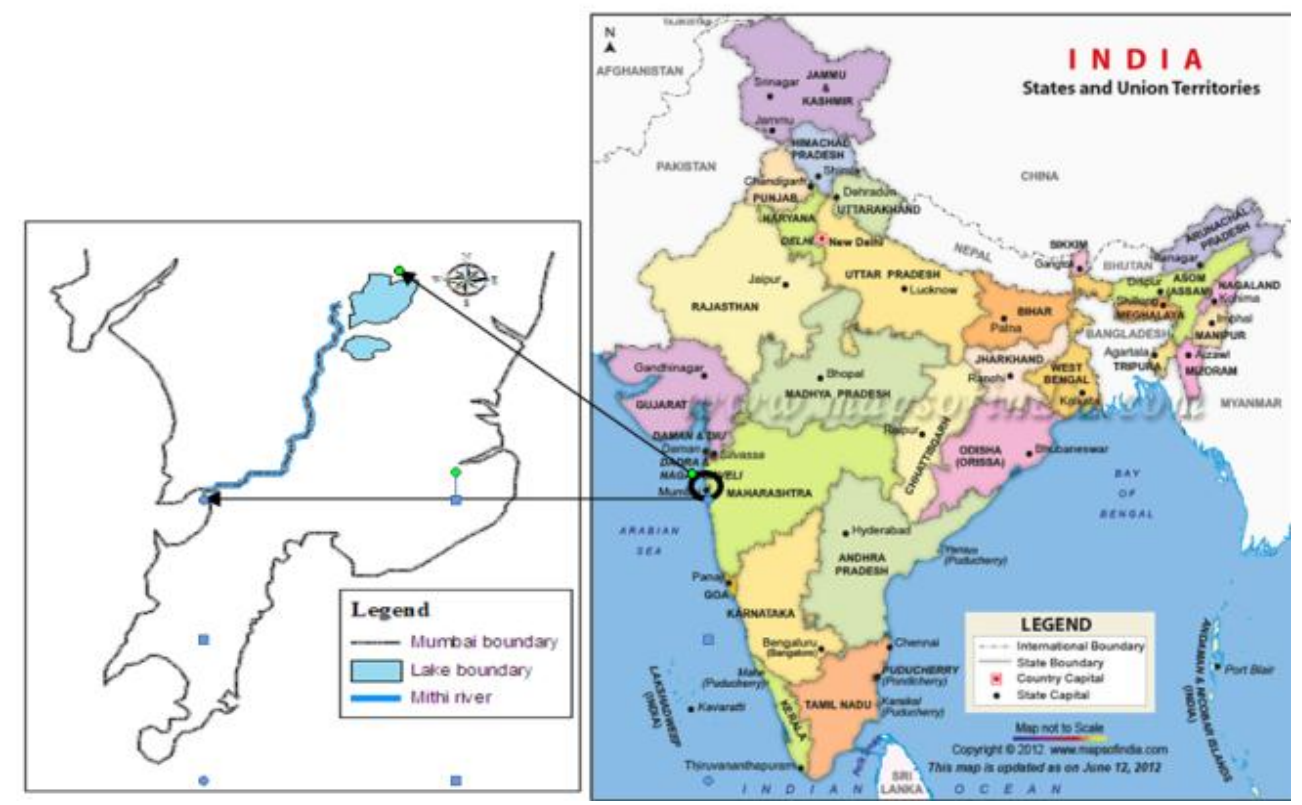

Figure 1: Location of Mithi River

III. Methodology And Data Used

HEC-HMS 3.4 is a numerical model that includes a large set of methods to simulate watershed, channels, and flood control structure behavior, thus predicting flow, stage, and its time of occurrence. HECRAS 4.0 is a numerical model that incorporates discharge as an input and calculates the water surface depth at key locations of the Mithi River. The following Fig 2 shows the methodology adopted for simulation of Mithi River basin using HEC-HMS 3.4 and HEC-RAS 4.0.

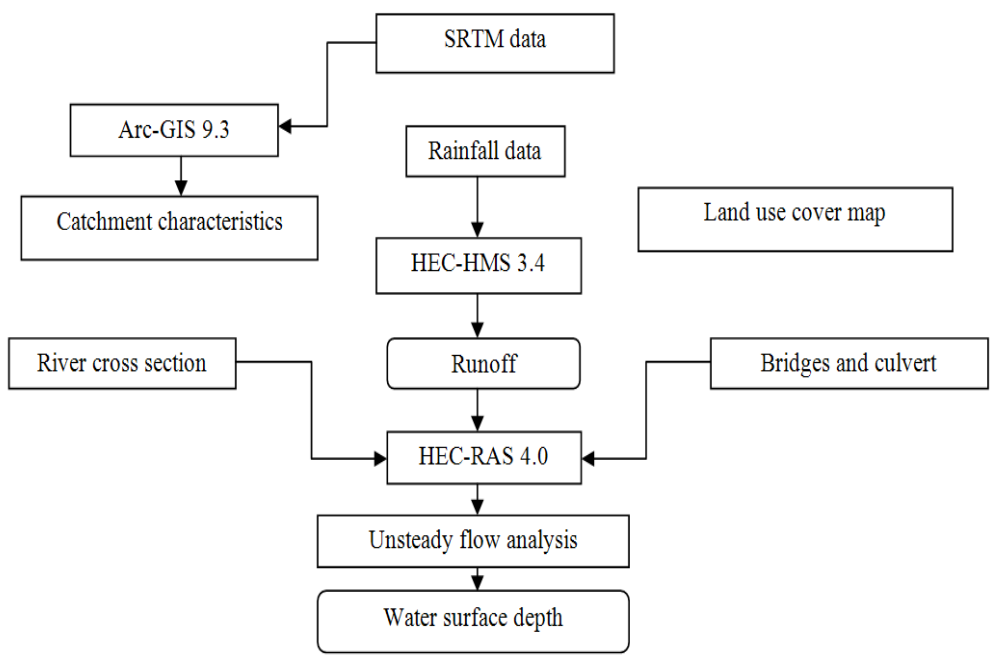

Figure 2: Conceptual framework of using HEC-HMS 3.4 and HEC-RAS 4.0

\subsection{Identification of catchment}

The catchment of the Mithi River was identified using contours prepared from DEM (Digital elevations model) of the study area. The total catchment area of the Mithi river found was $72.06 \mathrm{sq} \mathrm{km}(7,206$ hectare) and it was divided into 21 number of sub catchments as shown in Fig 3. 


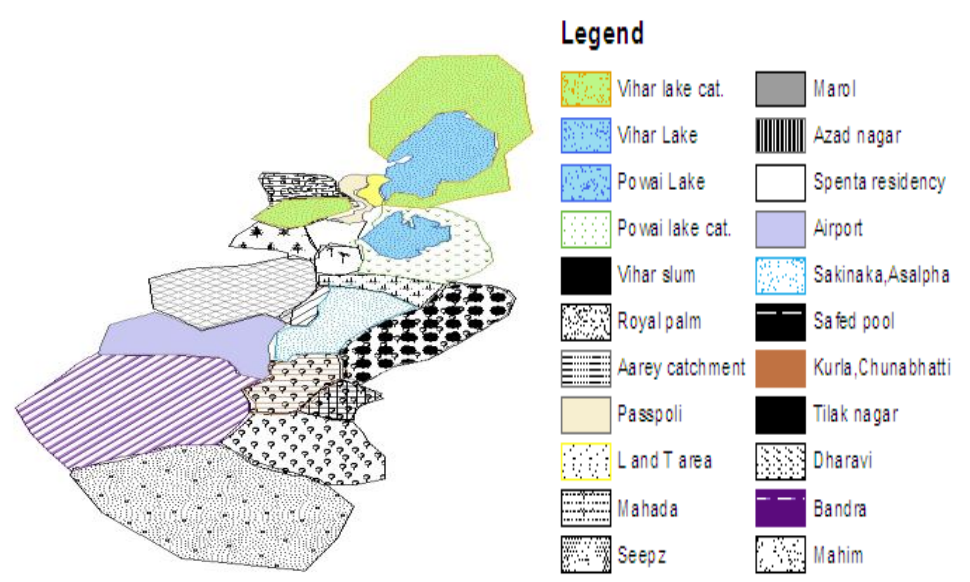

Figure 3: Mithi River catchment

\subsection{Preparation of land use cover map}

Mithi River catchment was divided into 28 zones. Surface of Mithi River catchment has been categorized into (Airport, Barren land, Built up area, Road and railways, and Water body). The land use cover map of Mithi River catchment has been shown in the following Fig 4 .

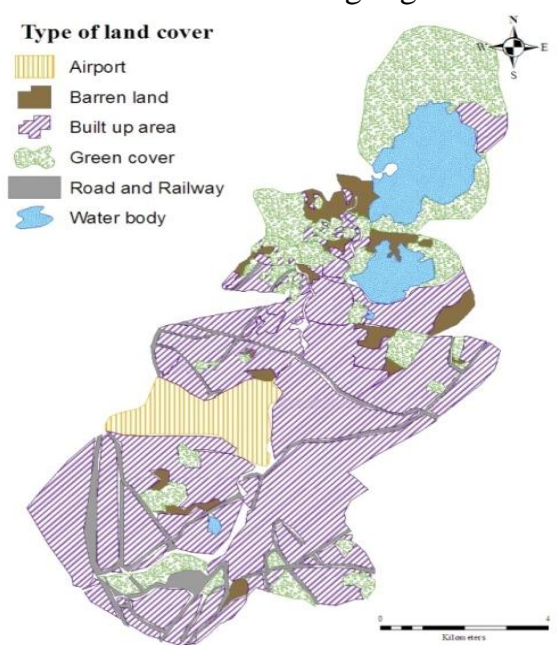

Figure 4: Land use cover map of the Mithi River catchment

\section{JVLR Detention Pond}

Contour level has been extracted at an interval of $0.5 \mathrm{~m}$ by using by using SRTM data ( $90 \mathrm{~m}$ resolution). Area vs. depth curve for JVLR detention pond has been prepared using these $0.5 \mathrm{~m}$ interval contours.

\subsection{JVLR detention pond weir}

JVLR detention pond weir is located at the outlet of Aarey catchment just upstream of the JVLR Bridge. It is used to detain the runoff coming from Aarey catchment and to release it during the time of low peak. The R.L of bottom of JVLR pond weir is $19.5 \mathrm{~m}$ while R.L at the top level is $23.5 \mathrm{~m}$. it detains the water level upto the R.L of $23.5 \mathrm{~m}$ behind the weir. The front view of JVLR pond weir has been shown Fig 5.

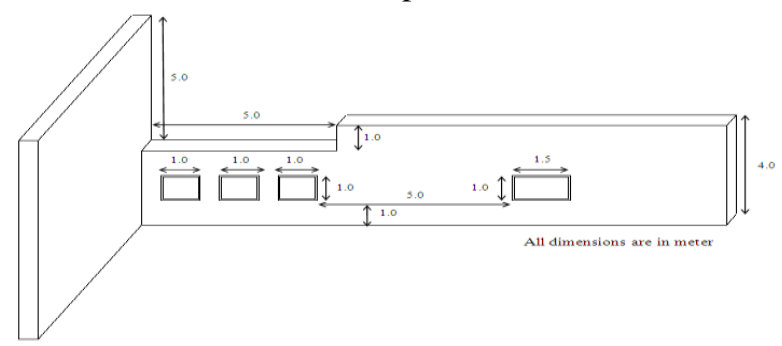

Figure 5: Front view of JVLR detention pond weir

The area vs. depth curve for JVLR detention pond has been shown in Fig 6 . 


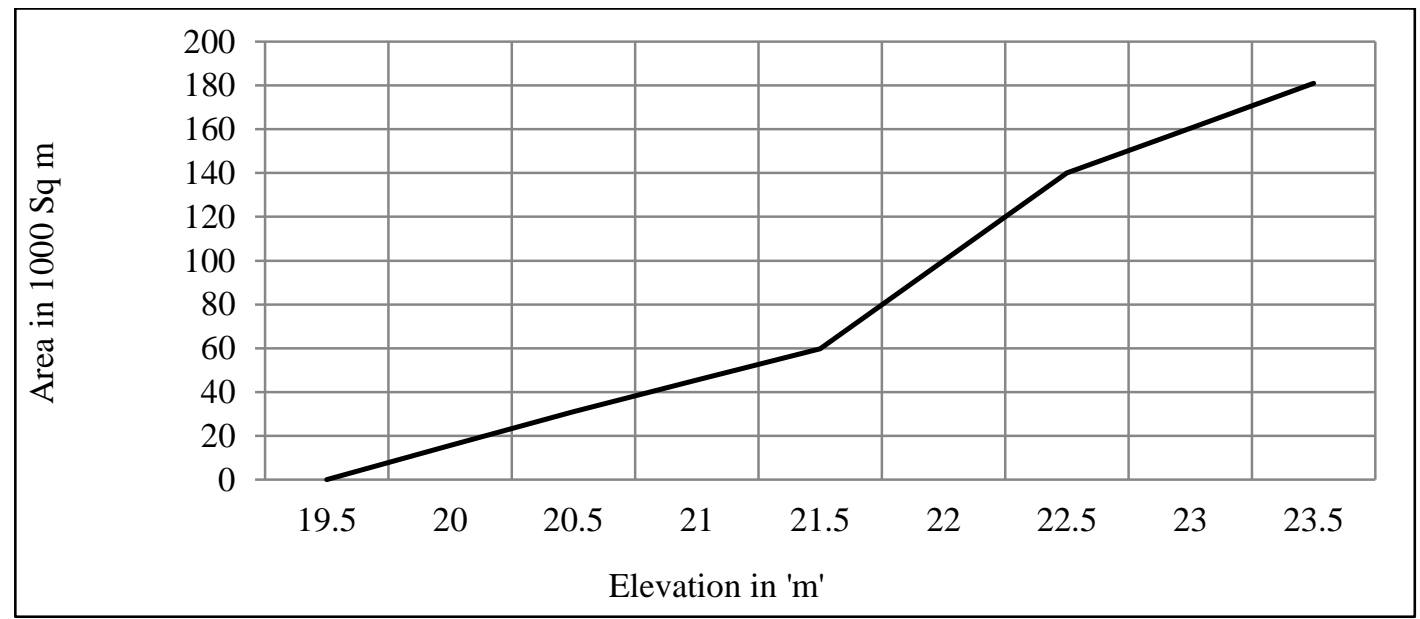

Figure 6: Area vs. depth curve for JVLR detention pond weir

\section{Calibration and validation of the model}

The Mithi River model has been calibrated at MCGM office, Powai and Krantinagar bridge site for the rainfall event (Figure 9) of $13^{\text {th }}$ July 2009 to $15^{\text {th }}$ July 2009).

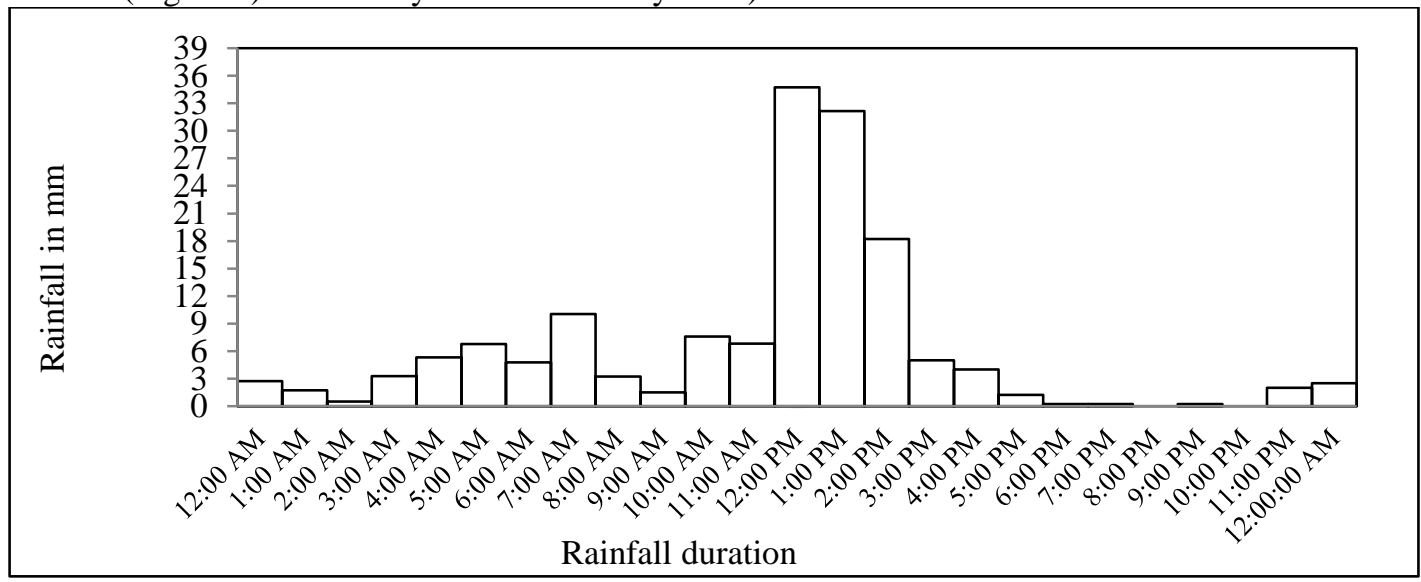

Figure 7: Hyetograph of rainfall from 13th July to 15th July, 2009

5.1 Calibration of Mithi River model at Krantinagar bridge site

The model has been calibrated for the rainfall event of $13^{\text {th }}$ July 2009 to $15^{\text {th }}$ July 2009 which has been shown in Figure 9.The observed water surface depth at Krantinagar bridge gauge site was $3.10 \mathrm{~m}$. Calibration of HECRAS 4.0 model Fig 8 showed water surface depth as $3.01 \mathrm{~m}$ at Krantinagar bridge.

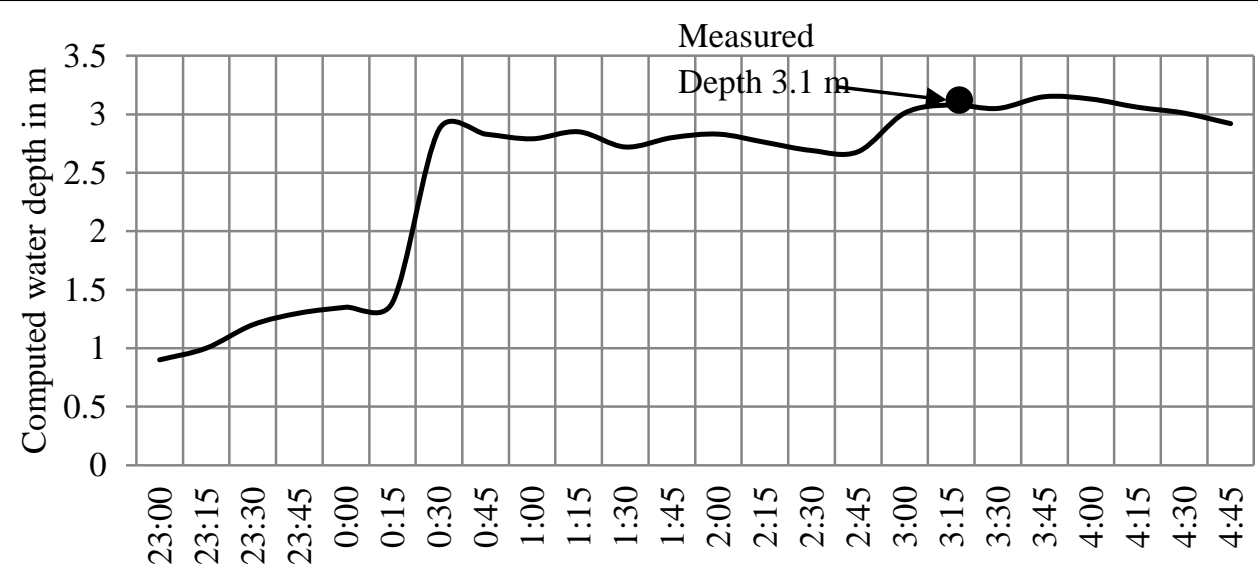

Simulation time

Figure 8: Calibration of Mithi River model at Krantinagar bridge site 


\subsection{Calibration of Mithi River model at MCGM office, Powai Lake}

Model was also calibrated at MCGM office. Powai Lake for the rainfall event as shown in Figure 9. The results obtained shows that the simulated water surface depth closely matches with observed depth. This model can be used as an effective tool for flood estimation in the Mithi River. The following Fig 9 shows the calibration of Mithi River model at MCGM office.

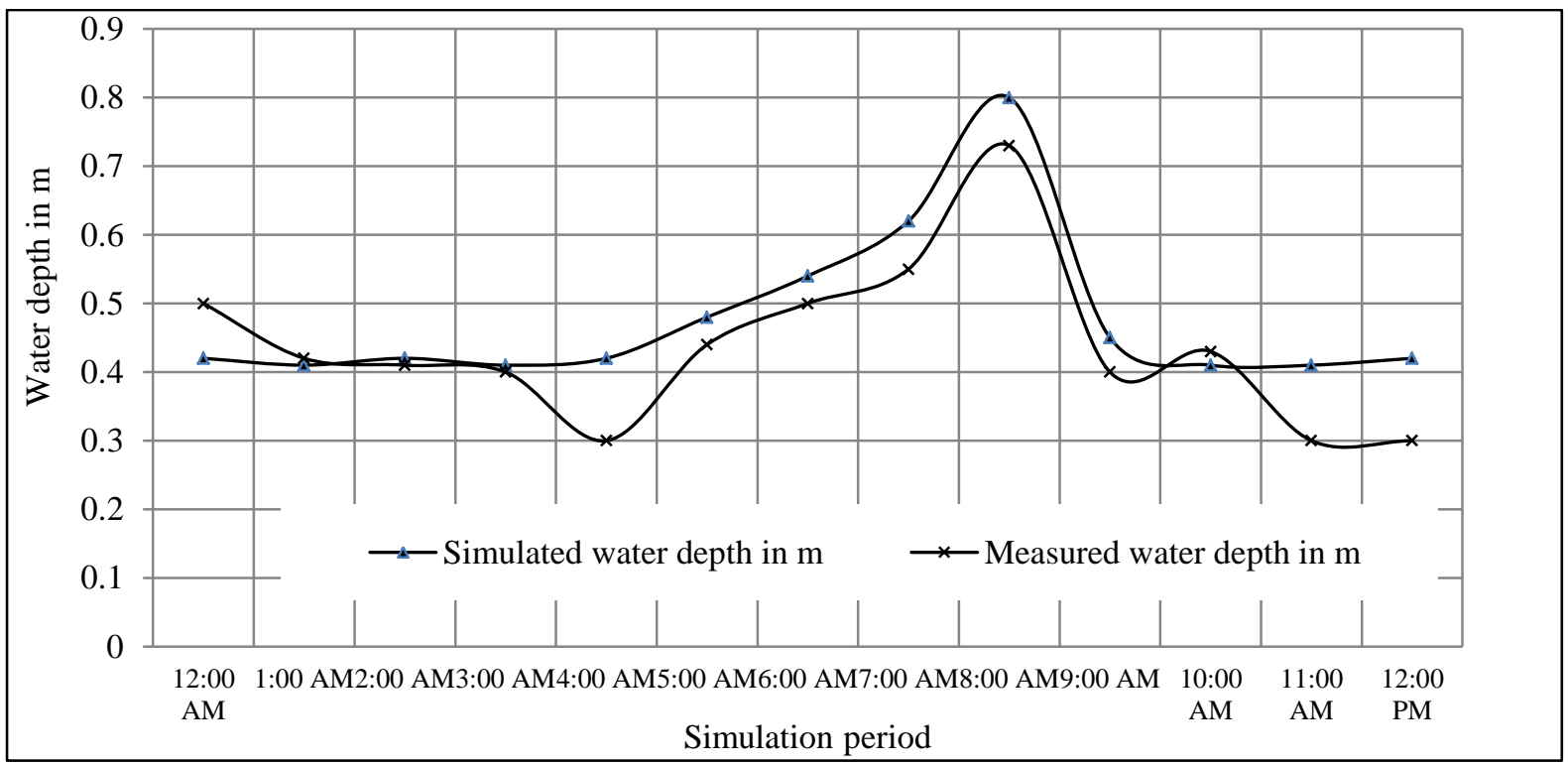

Figure 9: Calibration of Mithi River model at Powai Lake

\section{Results and discussions}

The flow and water surface depth have been simulated for various flood scenarios using the model HEC-HMS 3.4 and HEC-RAS 4.0 respectively for intensities varying from $25 \mathrm{~mm} / \mathrm{hr}$ to $200 \mathrm{~mm} / \mathrm{hr}$ in increment of $25 \mathrm{~mm} / \mathrm{hr}$ and results were obtained.

The following sections show the simulated results for the upper Mithi River catchment using HEC-HMS 3.4 and HEC-RAS 4.0.

\subsection{Efficiency of JVLR detention pond in reducing peak runoff at just downstream of JVLR weir}

Fig 10 shows the efficiency of JVLR detention pond in reducing peak runoff for various rainfall scenarios. Simulation of runoff at upstream and downstream of JVLR detention pond shows flood peak reduction. A result obtained shows that maximum peak reduction occurs at a rainfall of $50 \mathrm{~mm} / \mathrm{hr}$. JVLR detention pond reduces peak runoff by $21 \%$ at a rainfall of $50 \mathrm{~mm} / \mathrm{hr}$ for four hours duration. As the intensity of rainfall increases, the efficiency of pond in reducing peak runoff decreases. This is due to reason that, as the volume off runoff exceeds the capacity of pond; it overflows over the weir and contributes to peak runoff.

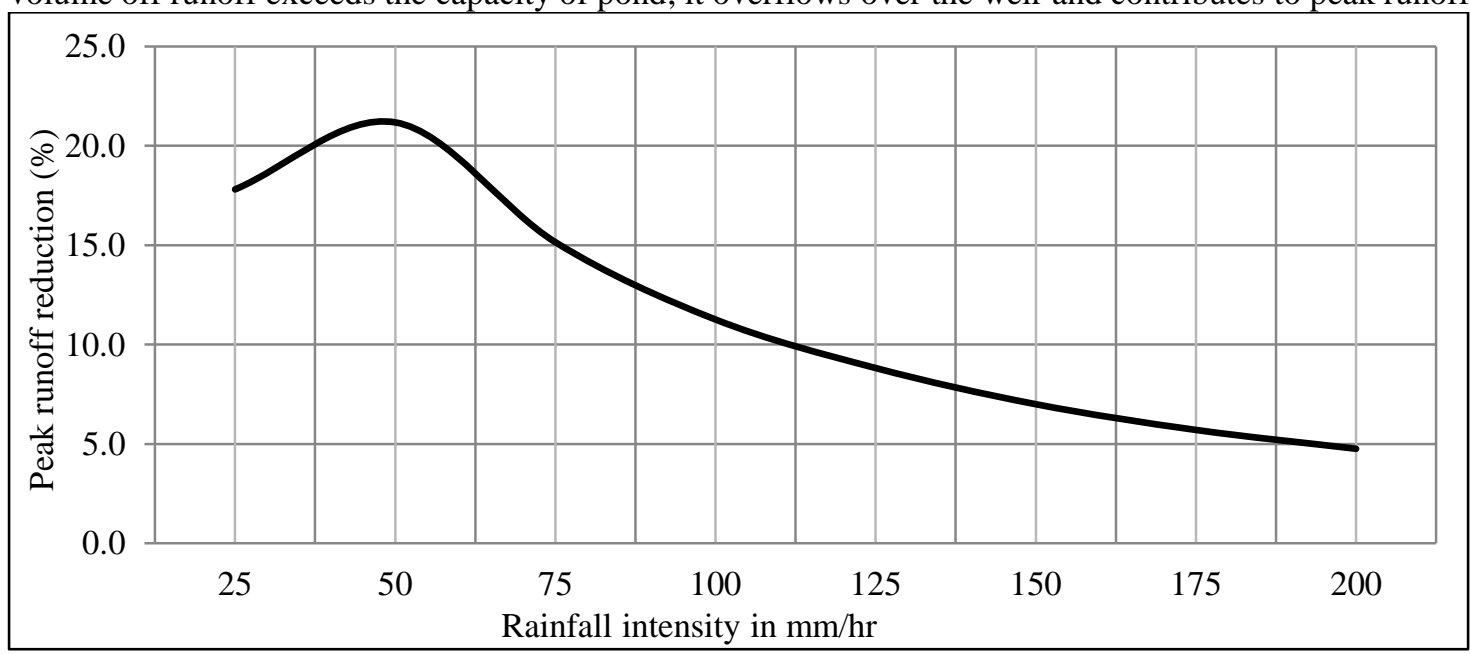

Figure 10: Efficiency of JVLR pond on reducing peak runoff 


\section{Conclusions}

HEC-HMS 3.4 and HEC-RAS 4.0 models have been used to demonstrate the simulation of flow and water surface depth at upper Mithi River catchment. The peak runoff has been obtained at downstream of JVLR detention pond with and without considering the effect of detention pond. The simulation result shows maximum peak reduction of $21 \%$ by JVLR (Jogeshwari-Vikhroli link road) flood detention pond. It has been seen that efficiency of JVLR detention pond decreases as the rainfall intensity increases above $50 \mathrm{~mm} / \mathrm{hr}$.

\section{Acknowledgement}

The authors would like to appreciate the editor and potential reviewers very much for their valuable comments and suggestions.

\section{Journal Papers:}

\section{References}

[1] J. Marsalek, B. E. Jimenez-Cisneros, P. A. Malmquist, M. Karamouz, J. Goldenfum, and B. Chocat, "Urban Water Cycle Processes and Interactions, IHP-VI Technical Document in Hydrology No 78, 2006, (UNESCO,Paris).

[2] K.Gupta, "Urban flood resilience planning and management and lessons for the future: a case study of Mumbai, India, Urban Water Journal, Vol. 4, No. 3, September 2007, 183-194.

[3] P. F. Hudson, and R.R Colditz, "Flood delineation in a large and complex alluvial valley, lower Panuco basin, Mexico", Journal of Hydrology, 280: 229-245, 2003.

[4] M. K. Yener, A. U. Sorman, A. A. Sorman, and A. Sensoy, "Modelling Studies with HEC-HMS and Runoff Scenarios in Yuvacik Basin, Turkey", Proc. River Basin Flood Management, DSI, 2007.

[5] Ghosh, F. L. Hellweger, "Effects of Spatial Resolution in Urban Hydrologic Simulations", Journal of Hydrologic Engineering, Vol. 17, No. 1, 2012, ASCE, DOI: 10.1061/(ASCE)HE.1943-5584.0000405.

[6] R. French, "The rational method: Past, present and future." Water Panel, The Institute of Engineers Australia (Queensland Division), Technical Session, Brisbane, Australia, 1-8, 2002.

[7] Z. Şen, and A. Altunkaynak, "Comparative fuzzy logic approach to runoff coefficient and runoff estimation", Hydrol. Processes, 20(9), 1993-2009, 2006.

[8] F. E. Hicks, and T. Peacok, "Suitability of HEC-RAS for flood forecasting", Canadian Water Resources, Journal, Vol.30, No.2, pp.159-174, 2005.

\section{Proceedings Papers:}

[9] R. Ranade, A. Hasan, "Increasing Storm Water Drainage Capacity of Mithi River and Mumbai City drains", 3rd Sound Practice Series, IIT Bombay, Mumbai, India. 